Euskal ikerketen aldizkaria | Revue d'études basques |

Revista de estudios vascos | Basque studies review

$20 \mid 2017$

Numéro XX

\title{
Sarrionandiaren ipuin arturikoak. Parodia, utopia eta desira
}

\section{Maria Lourdes Otaegi Imaz}

\section{OpenEdition}

\section{Journals}

Édition électronique

URL : https://journals.openedition.org/lapurdum/3549

DOI : 10.4000/lapurdum.3549

ISSN : 1965-0655

\section{Éditeur}

IKER

Édition imprimée

Date de publication : 1 janvier 2017

Pagination : 219-236

ISBN : 978-2-95534-135-3

ISSN : 1273-3830

Référence électronique

Maria Lourdes Otaegi Imaz, «Sarrionandiaren ipuin arturikoak. Parodia, utopia eta desira», Lapurdum [Linean], 20 | 2017, Sarean emana----an 01 janvier 2021, kontsultatu 03 septembre 2021. URL: http:// journals.openedition.org/lapurdum/3549 ; DOI: https://doi.org/10.4000/lapurdum.3549

Ce document a été généré automatiquement le 3 septembre 2021

Creative Commons - Attribution - Pas d'Utilisation Commerciale - Pas de Modification 4.0 International - CC BY-NC-ND 4.0 


\title{
Sarrionandiaren ipuin arturikoak. Parodia, utopia eta desira
}

\author{
Maria Lourdes Otaegi Imaz
}

\section{NOTE DE L'AUTEUR}

Artikulu honen egilea "Memoria historikoa literatura iberiarretan" Ikerketa Taldearen partaide da (IT-806-13). Bestalde, ikerle nagusi den "Gatazkak formatu txikian. Memoria historikoa genero ez hegemonikoetan" Ikerketa proiektuaren baitan burutu $\mathrm{du}$ (US 14/45). Azkenik, Londresen 2014ko Memories of the future batzarrean aurkeztu zuen txostena "Arthur in Iberia" du abiapuntu (College of Art and Design (UAL) \& Institute of Modern Languages Research).

\section{Berridazketa posmodernistak Sarrionandiaren ipuingintzan}

Ne sont que III matières à nul homme atandant, de France et de Bretaigne, et de Rome la grant. Jean Bodel, Chanson de Saisnes

Sarrionandiaren narrazio lanek luzaroan xarmatu dituzte irakurle euskaldunak, hiru ipuin bildumetan bilduriko hogeita hamar narrazio laburretan mamitu zen egilearen unibertso literario aberats eta askotarikoaren sareetan kateaturik. Sarrionandiaren narrazio fantastiko eta parodikoen oihartzun transtestualetan sarritan aurkitzen ziren XIX. mendeko narratiba erromantiko anglosaxoiaren oihartzunak, bereziki Robert 1 . Stevenson, Samuel Coleridge edo Herman Melvilleren idazlanenak, esaterako. Horrek iradokitzen zuen antzinate galduan kokaturiko narrazioen zaletasunak eraman gintuen $^{1}$ pentsatzera Sarrionandiak, Jon Miranderen narrazio eta poemetan bezala, iragan historikora jotzean lantze estetikoa eta tematika epikoa lantzen zituela pentsaraztera ${ }^{2}$. Ordea, egilearen idazlanek aurrera egin ahala, eta bereziki, 2011n argitaratu duen Narrazio guztiak (1979-1990) bilduman berriturik ikusita, irakurketa sakonago baterako zantzuak nabarmendu dira. Izan ere, euskal literaturako iraganeko 
egile edo pertsonaiak ardatz harturik eginiko narrazioetan bezala, Sarrionandiak istorio arturikoen bitartez, gure garaiko auziez mintzatzeko bide metaforikoa kausitua baitu. Horren susmoan jartzen gaituzte lehen bertsioetatik eginiko aldakuntzek batetik, eta bestetik, Hasier Etxeberriaren Bost idazle (2002) elkarrizketan, Robert L. Stevensonek "Gau baterako aterbea" ipuinaren itzulpena egin zuela aipatu izanak. Etxeberriari azaldu zionez, antigoaleko testamentuek Erdi Arora eraman zuten, eta handik Johan Huizinga, Herman Melville, Joseph Conrad, E.A. Poe eta Marcel Schowben "Haurren gurutzada" itzultzera eta testu haien berridazketak egitera. Merezi du egilearen aitormen horretan sakontzea.

2 Robert L. Stevenson-en ipuin horretan berridazketa historikografikoa egiten da, eta François Villon poetak gau ostatua eskaintzen dion aristokrata batekin izandako eztabaidaren berri ematen da. Idazle eskoziarrak Villonen balore ez-konbentzionalen paisaia zabaltzen du iritzi-trukatze fiktizio horren bidez. Ildo berean, jo zuen Sarrionandiak Bernard Etxepareren bizitzaren zenbait eszena "Disiecti menbra poetae", edota Beñat Goihenetxe Matalas-enak "Oroitzera eseri" ipuinetan imajinatzera ${ }^{4}$. Hauei erantsi behar zaizkie Durangoko herexiari buruzkoak, hala nola "Kristalezko bihotza"5, Marcel Schowb-en Haurren gurutzadaren oihartzuna dena, eta epilogo gisa Atxagak erantsi zuen "Jean Baptiste Hargous" narrazioaren lehen bertsio ezagunaren girokoa ${ }^{6}$. Bestalde, Herman Melvilleren Moby Dick-en eta Samuel Coleridgeren The Rhyme of the Ancient Mariner ikus genitzake ipuin horietako beste zenbait ipuinen lerro artean, hala nola "Arima naufrago bakartiak" edo "Marinel zaharra" izenekoetan.

Sarrionandiaren 1980-1990 hamarkadako ipuingintzaren aberastasunak kritikoen interesa piztu du eta ezin utzizko erreferentziatzat aipa genitzake arlo honetan Iñaki Aldekoak idatziriko "Joseba Sarrionandiaren ipuingintza" atala Mendebaldea eta narraziogintza $(1998,157-176)$ liburuan edo Jon Kortazarren J. Sarrionandiaren ipuingintza. Zuhaitz erromesa (2005). Bietan aurki daitezke aztergai ditugunak bezalako narrazioen testuarteko harremanen aipamen zehatzak. Iñaki Aldekoak Joseba Sarrionandiaren ipuinok Jon Miranderekiko harremanean aztertzen ditu (1998, 164-169), bien arteko aldea azpimarratuz, Parisko zuberotarraren epikarako zaletasunaren aldean, azpimarragarria baita Sarrionandiak ipuinotan garaturiko lirismo metaforikoa. Bestalde, Jon Kortazarren liburuaren izenburua "Amorante ausarta" ipuinaren pasarte batean oinarritzen da. Ipuin horretan Merlin Vivianez maitemindua agertzen digu haritz erraldoi baten ondoan jesarrita. Halere, ipuin horretako irudikapenak badu zerikusirik 1985ko Ni ez naiz hemengoa liburuko "Begia eta begirada" atalarekin, zeren hantxe aipatzen baitu Edward Burne-Jones pintore prerafaelitak margoturiko "Merlin liluratua" lauki ospetsua, eta zehazten baitu "Merlin zaharra arrama loratuen artean geratu eta Nyneve Lakukoa bere jakituriarekin aldentzen zaionekoa, elkarren begiradak ezin adierazgarriagoak dira (1985.81). Zuhaitz horren deskripzio aipagarria eta bikotearengana Pott taldekoen hurbiltzeak (J. Iturralde, B. Atxaga, etab) interes bizia piztu zuen ikerlariongan metafikzio esanguratsua zela iritzita (Otaegi, 1998, 18 eta 2000: 52). Egileak "zuhaitz erromesa" nabigatzailea edo bidaiari izango litzatekela aipatzen zuenez, autoreferentzia gisa interpretatu nuen ${ }^{7}$. Zuhaitz erromesaren autoirudikapenak badu garapenik "Antzara bat da imajina" izeneko Ni ez naiz hemengoa liburuan, non ikus daitekeen zuhaitzaren irudia Joan Vinyoli poeta katalandarraren poema batetik hartu zuela "Jo no sóc més que un arbre que s'allunyà del bosc". Eta honela itzuli zuen Sarrionandiak: "Oihanetik aldendu zen zuhaitza besterik ez naiz, 
itsasoko abots sakon batek deitua. Bakarrik, urbazterraz bestaldeko haizeei eskaini dizkiet ene hostoak...". Saio poetiko laburra eskaintzen dio jarraian poesiaren ezagutza ahalmena azaltzeari, izan ere, bere iritziz, "poesiak psikiatriak baino errealitatearen ezagumen handiagoa ematen du, nahiz eta informazio gutiago, esperientzia zientzia baino beti egiatiagoa delako, imajinazioa zientzia baino ahaltsuagoa delako" (1985:141).

4 Testuartekotasun ageriko horren bitartez, egileak berridazketa saio guztiz iradokiorrak proposatu zizkion irakurleari, "tradizioa esperimentalismo literariorekin elkartuz", eta "elementu material guztiz lokalak Europako tradizio literarioarekin eta mundu guztikoarekin harremanetan jarriz". ${ }^{8}$

5 Artikulu honetan zehar, Sarrionandiaren hiru ipuin bilduma horietan kokatzen diren lau narrazio arturikoak batean irakurriko ditugu eta 1983-1990 arteko zenbait ideia literariorekin harrmeanetan jarriko dugu, bereziki $\mathrm{Ni}$ ez naiz hemengoa egunkari modukoan adierazitako argumentuekin, antigoaleko elur horien zamapean ostenduriko "kristalezko bihotzei" igartzea dugu helburutzat, edo modu dokumentatuagoan esateko, "ez errealitatea deskribatzearen errepidetik, baizik eta alderantziz, errealitatea sortzearen estratatik" (2011:8) jo zuela iradokitzea. Izan ere, egileak Etxeberriari iradoki moduan, ez baitzuen literatura ideologia baten azalbide gisa hartzen, mundua kritikoki argitzeko ahalmen espezifikoak dituen espazio gisa baizik.

\section{Metafikzio historiografiko parodikoak}

"Parodia egitea erraza da, ezin da errazagoa izan. Tristea ere bada, Ia eginda aurkitzen da."

(Fool Bufoia)

6 Sarrionandiaren "Ezpata arragoan" narrazioak daraman epigrafe honetan islatzen den bezala, mundu arturikoaz diharduten narrazioek osagai posmodernitatearen munietako bati atxikia ageri zaizkigu, parodiari alegia. Epigrafe horretan adierazten zaigu errealitateari bihurrikeria handiegirik egin gabe eta den bezalakoxea erakutsi nahi duenean, idazleari parodia tristea sortzen zaiola, naturalitate osoz.

7 Arthur erregearen osagai epikoak maila apalenera ekarriak aurkituko ditugu: Arthur eta Ginebra errege-erreginak Etxaburuko dorretxe abailduan bizi dira, Fool izeneko bufoia zerbitzari bakarra dutela. Nekazari bizitza egiten dute, gehienbat, naturaren erdian, basoak eta elurrak inguratuak. Halere, osagai anakronikoek adierazten digute ez dela narrazio historikoa: erregeak kobrezko koroa janzten duen arren, baserritarren abarkak ere jazten ditu, eta idi parea hartuta joaten da Gasteizko ferira. Garai bateko baserritarren legera bizi da eta San Juan suaren erritoa burutzen ikus genezake, baina aldi berean, garai mitikoetako ohore kodeari lotua jarraitzen du irmo. Hala, iraganeko Kameloteko Urrezko Aroa oroitarazten dio bufoi-zurikatzaileari, eta, handikeriaz, kronikalari profesionalak kontratatzeko ametsak egiten ditu herriaren historia komeni den bezala idatz dezaten. Bestetik, ordea, gure garaiko janzkerez ere agertzen dira eta etxeak irratiz hornituta daude, Maoren liburu gorria irakurtzen du pertsonaia gaztea iraultzaileak, Galahad gazteak, eta San Juan suan egunkariak eta telegramak erretzen dituzte dorretxekoek...

Hori bezalako iraganaren berreraiketa anakronikoek badute posmodernitatean leku propio bat, izan ere errealitate garaikidearen konplexutasunak eta prozesu kulturalen aldaketa azkarrak osoki ulertzeko ezintasuna ekarri dizkigu, eta ondorioz, lekuen 
aldiberekotasuna, errealiatearen fragmentazioa eta hura osotasunean birkonfiguratzeko ezintasuna heldu zaizkigu. Hitz batean, halako deserosotasun eta ezintasun esperientzia bat. Frederic Jameson literatur teorialariak zioenez, gure garaian ez gara gauza komunikazio sare deszentratu, multinazionala eta globalaren mapa eraikitzeko, eta geu banako moduan, horretan atzipetuta sentitzen gara ${ }^{9}$. Horregatik posmodernitateko idazleen fikzioetan espazio edo une kulturalak konprimitu egiten dira, eta hauei barne-koherentzia logiko-tenporala emateari uko eginik, fragmentu edo zatiak proposatzen dituzte arte-sortzaileek: ezegonkortasunaren lekuko bilakatzen dira.

9 Anakronia posmodenistetan arrazionaltasun moderno gehiegizkoaren arazoak azpimarratzen dira, eta estatu boteredunaren kontrol mekanismoak gai zentral bilakatzen ditugu. Horregatik, ukroniak sarritan erregimen totalitarioen arrazionaltasunaren eta deshumanizazioaren alegoria izaten dira. Informazio eta salgaien trasferentziaren azkartasunaren aldeko apustuak gizarteari zorabio kulturala eragiten dio $^{10}$. Horregatik, fikzio posmodernoetako atmosferetan hilen eta bizien arteko mundu hauskor bat errepresentatzen da, amestearen eta esna egotearen artekoa dena, iragana, garaikoa eta etorkizunekoa dimentsio bakarrera konprimitzen dituena, Sarrionandiaren ipuinetan ikusiko dugun moduan.

10 Hartara, espazio eta aroen nahiz pertsonen kokapenaz desorientazioa eragiten zaio irakurleari, ezer ez baita narrazio erromantikoetan edo erdiaroko fikzioetan espero zuen bezalakoa. Sarrionandiaren ipuinotako pertsonaia posmodernoek ez dezakete euren errealitatea menderatu, itxaropen oro galduta agertzen dira eta arazo misteriotsuetan sartuta agitzen dira. Espazio erreal eta hurbiletan kokatzen dira (Durango, Izurtza, ...), baina errealitate horren egonkortasunaren zalantza harrotzen da berehala, eurak baino indartsuago den zerbaitek dantzarazten baititu: patu tragiko baten menpe ezarriak dira, beren eginahalak gorabera. Mugarrako harkaitzaren barrenean dagoen Etxaburuko dorretxean kokatu da pertsonaia arturikoen erbestealdia, baina garai mitiko batean bizi dira: iraganeko, garaiko eta etorkizuneko zantzuak biltzen dira euren errealitate paradoxiko eta kezkagarrian.

11 Ondoko pasartean ikusten den bezala, Arthur baserritar xumea da soroan, baina errege bat etxe barruan, bere bikoiztasun horrek, jerarkia sozialaren iraupena iradokitzen du, soroan lankide diren Arthur eta Fool etxe barruan errege eta bufoi baitira. Harreman horretan sakontzen du Ni ez naiz hemengoa liburuko "Errregea eta bufoia" izeneko ataltxoan, eta elkarren behar handia dutela iradokitzen du, mundu osoko agintariek alboan gizontto deformeak izan dituztela oroitaraziz. Bufoiak babesa hartzen du nagusiarengandik eta ordainetan erregearen, gizarte arauen eredua den horren ifrentzua erakusten du "alderantzizko ispilu" baten moduan, guziz ero eta deformea. Honela ondorioztatzen du "Ia pertsona bakarra osatzen dute bufoiak eta eta erregeak, bakarra eta bikoitza. [...] Boterearen eskizofrenia? Dena dela, erregeak bere beste kontzientzia alboan eduki behar duelako dela sumatzen da. Bere buruarentzat, bere beste aldea, bere giza txatartasuna berarengandik lekora ikusi behar du, bere burua garbiago ezagutzeko." (1985:156)

"Arthur erregea, soroetako lanak amaitu, ukuiluko abereak gobernatu, eta ilunabarreko tenore hartarako arropaz aldatuta zegoen. Abarkak, galtza zaharrak, gerriko beltza, alkandora eta txapela erantzi eta tunika eskarlata jantzia zuen. Marta-larruz forraturiko tunika gorrimin hura, eta koroa ere buruan zeukan" (198)

Posmodernitateko eleberri historikoek problematizatu egiten dute ezagutzaren posibilitatea eta zientzia historikoak bere zentraltasun hegemonikoa galtzen du. 
Horregatik, lehendik idatziriko narrazioen berridazketa fiktizioek soilik erakutsi dezakete haren funtsezko "gezurra". Testu historikoaren "artefaktotasuna"ren argudioa guztiz garrantzitsua da zientzia sozial posmodernistetan, historiaren eta literaturaren arteko muga lausotuz, errealitatearen eta fikzioaren arteko muga ere ezabatzen baita eta errealitatea bera ere ilusio gisa aurkezten da. Erreferentzialiatearen krisiak lehen planoan ezartzen du testu literarioaren artifizialtasuna ere, eta errealismoaren ezintasuna frogatu ondoren, irudimena legitimatzen du errealitatearen errepresentazio gisa. Ildo horretan, "Ezpata arragoan" izeneko ipuinean Errege Arthurrek eta Fool bufoiak garatuko duten elkarrizketan Kamelot erresumako Urrezko Aroaren kronikagileen funtzio propagandistikoaz dihardute, lehenik, eta ondoren, Euskal Herrian jendeaz Foolek esaten duenean "esperoan egonen dela beti”, "zerbaiten faltarekin" biziko direla (2011:202). Ordea erregeak erabakitzen du arazoa historiagileek konponduko dutela:

"Izkiriatzaile bat ekarri behar diagu. Hor, Bitorian, Durangon edo nonbait izanen duk gizonen bat letrak idazten dakiena, gure erresuma zaharraren historia latinez konta diezagun, esperantza zer den eta zer espero behar dugun argi diezagun" (2011:202)

Hitz horietan, erregearen prozeduraren "logika"z gain, Kameloteko erresuma eta Euskal Herrikoa bat eta bera direla suma genezake. Errege baita bera edonon: "Rex quondam, rexque futurus"11. Gure erresuma baketsua eta behin betirako oreka perfektua duen gobernuburu da Arthur, lehen, orain eta gero. Halere, Postmodernitateko narrazioetan berridazketa historiografikoetan pertsonaia historiko-mitikoek ez dute gehiago distira epikorik, eta egilea bera ere sublimitatearen Parnasotik eraitsia izango da: artifizio literarioa da bere testuak etengabe seinalatzen duena eta testuartekotasun jokoak bere "taumaturgo" itzala ezabatuko du ${ }^{12}$.

14 Intertestualitatearen eta metafikzio historiografikoen ekarpenez, garai posmodernoetako indeterminazioa areagotu da eta aurkezten zaigun testua ez da areago autonomoa izango, testu sare zabalarekin konektaturik dagoen fragmentu hipertestual bat baizik. Esate baterako, Arthur eta Foolen arteko elkarrizketan Cameloten kronisten zerrendaren berri ematen zaigu: "Galfridus Monemutensis, Chretien de Troyes, Thomas Malory, Mark Twain, Alvaro Cunqueiro..." (1911:203). Hala, aitortzen ditu Sarrionandiak bere eszena multzo txikia den fragmentu-sortari zentzu osoa ematen dieten hipotestuak, Arthur erregearen Urrezko Haroaren era bateko eta besteko kronistak. Begoña Montoriok Ni ez naiz hemengoa liburuaren gaztelaniazko itzulpena egin zuenean, Sarrionandiak hitzaurrean liburuak jatorrizko akatsak zituela esan zuen autoironiaz: "como ese tan frecuente en nuestros días de convertir la escritura en una "casa de citas", como algunas opiniones de errada contundencia, como diversas divagaciones sin fundamento" (1991:16). Halere, iruzkin literario horiei eta aipamen ugari horiei esker, bere ipuinetan modu metaforikoan adierazitakoa hobeki balora genezake. Bereziki interesgarri dira iragan historiko-mitikoaren berridazketa modernoei buruzko hausnarketak eta hizkera metaforikoaren eta imajinazioaren ahalmenei buruzko iruzkinak Arthur erregaren mitoaz berak eginiko ipuinak argitzerakoan.

15 Egiaz Arthur izeneko errege baten zantzuak badiren arren, Kamelot edota Merlín bezalakoek irudimenaren fruitutzat hartzen dira. Arthur V. mendean britainiarrak saxoien menpekotasunetik liberatu zituen erregetzat dauka tradizioak. Orduan hasi bide zen Urrezko Aroa deituriko aldia, eta erresuma bat ezarri zuen kristau zaldungoaren legeak nagusituko diren sasoia, baina Mordred bere hiloba/semearen 
traizioak hondatu egingo ditu bere egitasmoak. Geoffrey de Monmouth idazleak bilakatu zuen Arthur heroi erromantikoan (Historia Regem Britanniae, XII) eta Erdi Aroaren amaierarako hedatua zen Arthurren istorioen memoria Europa mendebaldeko osoan, itzulpen, gehikuntza eta aldakuntza generiko ugarien bidez, eta pertsonaia nahiz osagai legendario gehiago bilduz. Besteak beste, aipagarri dira ingelesezko lehen bertsioa egin zuen Layamon(c.1200), Geoffrey of Monmouth eta, azkenik, Malory (Le Morte de Arthur, 1475) testuinguru berri batean kokatu baitzuen elezahar zeltikoa ${ }^{13}$.

Zinema eta literatura nahiz komikiaren bidez irakurlearen begi-ninietan iltzatuak dauden narrazioen sarean kokatzen ditu Sarrionandiak bere testu zatiok. Irakurlearen ezagutzaren tarteetan kokatuz, bere berridazketa parodikoak eragiten dituen aldakuntzen bidez mundu heroikoari begirada kritiko zorrotza eskeintzen dio. Historiari edo leiendari modu irreberentean hurbiltzen zaio Sarrionandia; halere, ez dauka beretzat egiaren pribilegiorik, berez, historiografia ofizialaren alde iluna erakustea du helburutzat, eta historia produktu kultural eraikia dela erakustea du jomuga nagusi. Horren harira dator kronista arturiko kanonikoen aipamena, eta ondoren gai arturikoak begi kritikoagoez begiratu dituzten Mark Twain edota Cunqueirorena bezalako lanak gogoratzea. Lehenak, Twainek, A Connecticut Yankee in King Arthur's Court (1889) narrazio fantastiko eta komikoa idatzi zuen. Denboran zeharreko bidaia egiten duen protagonista iparamerikar batek Arthurren garaikoei teknologia garaikidearen abantailak erakutsi nahirik sortzen dituen nahasteak ditu kontagai, zientzia-fikzio generoaren lehen narrazioa osatu zuelarik, zenbaiten iritziz ${ }^{14}$. Beste zenbait idazlek, aldiz, pertsonaia arturikoak etorkizuneko denboretara eraman dituzte, hala nola C. S. Lewisek That Hideous Strength (1945) eleberrian, Merlin aztia etorkizuneko Ingalaterran abentura espazialetan kokatu baitzuen. Denboraren tuneleko atzera-aurretan kokatzen dira Sarrionandiaren narrazio hauetako batzuk ere, bereziki "Amorante ausarta" (1990) izenekoan aurrerantz egiten badu ere, beste hiruretan iragana eta oraina elkarturik aurkezten dira.

17 Argigarria da Ni ez naiz hemengoa liburuan agertzen den "Literatura anakronikoa" ataltxoa (1985:54-56). Bertan, xeheki mintzatzen da Maloryren testuan dauden anakroniez, berez hamar mende lehenagoko Arthuroren istorioak XII mendeaz geroztikoak diren jantziak eta zalduneria arauak sartu baitzituen. Halaxe dio Sarrionandiak: "Thomas Maloryk iraganean imintzen du bere istorioa, kronologiaz eta epeetaz axolatu gabe edo, hobeto esan, kronologia eta epeen gainetik. Orduan obrako gai eta ardurak XV. mendekoak dira, Thomas Malory bere garaiko gaiez ari baitzen, nahiz eta gauzok iraganean situatu, baina bere narrazioa anakronikoa da, denbora haro ezberdinak nahasten dituelako." (55). Ondoren, John Steinbeckek idatzi nahi zuen Arthurren historia idaztean, Maloryk bezala iragan anakronikoan kokatzea erabaki zuen. Bere hausnarketen arabera, "literaturarako iragana anakronikoa izan daitekeela pentsatu zuen. Hau da, Arthur erregea ez dela haro konkretu batetan situatu ahal, baizik eta gure munduaren iragana den oihal zabal horretan" (1985:65). Sarrionandia ere bide horri lotu zaio. Eta aurrerako iraganaren oihalaren metaforan sakonduz zera diosku:

"oihal horrek aro ugari iragan ditu, aro bakoitzak bere kolorez tindatu duela, eta giza historiarenak ezik giza izakeraren zeinuak isladatzen ditu, zeinu hain hilkor eta hain eternalak. Behar bada literaturan iragana kondatzen deneanaro mitikoa azaltzen da. Oihal mitikoa, iraganaren oihala, ehuntzen ari garen imajinazioaren oihala da." (56) 
de, intertestualitateari buruzko informazioa osatze aldera, gogoratu behar da halaber, zeltismoarekin batean heldu direla narrazio arturiarrak galiziar literaturara. Vicente Risco-ren ideologian duen eraginaz gain, beste hainbat idazleren izenak dira aipagarri ildo tematiko honetan. Besteak beste, Xose Luis Mendez Ferrin, Alvaro Cunqueiro, Gonzalo Torrente Ballester, Darío Xohan Cabana (1952-) eta Carlos González Reigosa (1958-). Xosé Luís Méndez Ferrínek (1938-) modu berritzailean berridatzi zuen Perceval zaldunaren historia atmosfera enigmatikoan kokatuz eta osagai surrealistez inguratuz. Amor de Artur (1982) liburuan Arthur, Ginebra eta Lanzeloten arteko maitasun triangeluari buruz idatzi zuen ${ }^{15}$. Ideologikoki hurbilago izan zezakeen arren, Xose Luis Mendez Ferrinen obratik baino hurbilago daude Sarrionandiaren Álvaro Cunqueirorengandik (1911-1981). Izan ere, gogoan hartzekoa deritzogu Hasier Etxeberriari eginiko adierazpenetan beragan eragina izandako nazioarteko hainbat idazle bikoteen artean, galiziar literaturako Celso Emilio Ferreiro eta Alvaro Cunqueiro aipatu zituela ${ }^{16}$.

Álvaro Cunqueirok, ziklo arturikoaren zaletasun handia izan zuen eta bere lanetan Merlinen mitoaren interpretazio berritzailea egiten zuen. alde batetik Merlín e familia (1955) eleberria, eta bestetik, egunkarietan argitaratu zituen zenbait artikulu eta narraziotan Merlín izan zuen beti subjektu eta interesgune. Sarrionandiaren ipuinetan harekiko intertestualitatea adierazten da. Beharbada Laberinto y Cía (1970) liburuan berrargitaratu ziren "La tumba del Rey Arthur" eta "Merlín en Carmarthen" izenekoak dira guretzat adierazgarrienak ${ }^{17}$. Izan ere, Cunqueiroren estilo zantzuak topatzen ditugu Sarrionaindiaren ipuinotan. Hark ere fikzionalizatu egiten du paisaia geldi bat, eta teatraltasunez jazten du, atmosfera erromantikoan bilduz:

"La niebla que venía del pantano en aquel triste anochecer, se teñía de rojo al avanzar sobre el que había sido campo de batalla. En el cáliz de una amapola, como una extraña gota de un misterioso rocío, yacía un verde ojo de Galván sin Tierra." ("La muerte de Arturo", Laberinto y Cia, 1970, 271)

Cunqueiroren prosak dituen ezaugarriak hurbil daude Sarrionandiak bere narrazio horietan garatzen duenetik eta, agian, zenbait irudiren dramatikotasun expresionista ere bai, hala nola, Galahad gaztearen begi urdinak, bere aita Lancelotenen berdinberdinak, ikusten dituenean Ginebra erreginak beleen mokoetan $(2011,61)$. Baina nola ez gogoratu, gisa berean, Alosko dorreko Beltranen alaba doakabeaz, Ginebra Erreginaren irudia ikusiz dorretxeko lehioetan beleak ezin uxatuz. Bestalde, estilo literario horren ezaugarrietako bat gelditasuna eta ekfrasirako joera deskribatzaileaz argitasun ugari eman zituen egileak $\mathrm{Ni}$ ez naiz hemengoa liburuko atal ugaritan non pinturak eta bereziki koloreak eta irudimenak bere ideia poetikoetan duen garrantziaz luzaro mintzatu zen. Azpimarragarri da, esaterako, "Unibertsoa, kolore sinfonia" izeneko atalean dioena: "Obra literarioa koadro bat bezala margotu behar da, koloreen oreka, irudiaren osotasuna hatzemateko.” (1985:103)

21 Mendebaldean prestigio handiko tradizio narratiboari lotzen zaizkio biak eta euskal baladen irudi eta hizkeraz fusionatzen du Sarrionandiak Bretainiako materia, Cunqueirok hizkera trovadoresko galiziarrarekin egin zuen modu berean. Kanon estetiko propioaren arabera egokitu dute narrazioa, eta nork bere lurraldera ekarri, aldi berean narratiba fantastikoaren bidez ihes egiten diotelarik errealismo mimetikoari, anakronikoa den errealitate mitiko berezia bisortuz. Cunqueirok eta Sarrionandiak Arthur, Ginebra, Lanzelot edota Merlinen inguruko legendak gure garaiotara ekarriz edota etorkizunean kokatuz, nolabaiteko malenkoniaz janzten dute 
inguratzen dituen paisaia, zalantzaren eta indeterminazioaren poesia eratxekiz. Izan ere, Sarrionandiak iradoki bezala, iraganeko oihaleko mito horietan giza historia eta giza izakeraren zeinuak baitaude bilduta. Errekreazio literario horrek ordea, Sarrionandiaren ideia literarioen arabera funtzionalitate bat $\mathrm{du}$, lehen denbora mitikoa oroitzea ez da aski, hura berbizi egin behar du literaturak, bere gaitasun eraldatzailea bete dezan, ez baita asmo ludiko estetizantez birsortua.

"Beretzat [gizaki primitiboarentzat] lehen denbora bat dago, denbora mitiko, denbora sakratua, eta gauza bereziren bat nahi duenean, ezagumenean zein ekitean, denbora horixe errekuperatu behar du. Ez oroitu soilik, baizik eta berbizi. Vainamoinen zaharrak burdina asmatu zueneko erritoaren bidez burdin zauria sendatzeko. Soro eta larreetako deabruak uxatzeko, lehen denboran heroeak uxatu zituenenko mitoa oroitu behar da, gu eta lehen denboraren artean lokarri den kantu zaharren bidez" (1985:54).

Horretarako, Sarrionandiak estetikoki nabarmengarria den prosa dotoreaz baliatzen da, balada zahar (Milia Lasturko, Mondragoko erreketaren kantak, Alostorrea, ...) edota balada berriagoen irudi eta gaiez ere bai (Oreina bilakatu neska), hitzaren eta irudien oihartzunaren magiak sortzen duelarik irakurketa interpretatibo baliotsuetaranzko ildoa. Elaborazio literarioak lehentasuna emango dio kontalariaren ikuspuntu liriko subjektiboari eta "miresgarri" ari. Baina ez da fantasia iheslaria edo ebasiozkoan murgiltzeko egina, zeren gertakarien laztasunak, absurduak eta inkoherentzia espaziotenporalek eragozten baitute lilura mimetiko hori, irakurlearen ikuspuntu kritikoari dei eginez. Caballero Bonaldek Cunqueiroren estiloaz emaniko iradokizunari jarraituz ${ }^{18}$, nahitara kutsatu du testua dotorezia erretorikoaz eta inkongruentzia diegetikoaz, irakurlea atzipetua gerarazteko Avalongo lanbro artean, hausnarketa luzatu eta subjektibitatea nagusi den irakurketa metaforikoaren eraginpean jartzeko.

\section{Desira eragotziak}

Hizkera apain horrek, ordea, agerian uzten du gorteko bizitza dotorea eta heroi ausart eta duinen ohore kodeak agintzen duen gizarte antolakuntzaren egitura bidegabea. Gizarte ierarkizatu absurdua erakusten du, modu inkoherentean dirauen ohorezko kode zaharkitu baten arabera bizi garela iradokiz. Hala, erbesteraturik, zaharturik eta arruinaturik bizi diren pertsonaia arturiko horiek euren arteko harreman-egiturari eusten diote, biolentziaren erabilera delarik bitarteko nagusi. Errege da Arthur edonon eta beti, eta Fool bufoia, berriz, polizia, espia eta historialari da haren zerbitzuan, beti menpeko eta espaz betea. Merlinek, azkenik, erregeari baliabide teknikoak eskaintzen dizkio. Eta Ginebraz, zer? Ohargarri da 1983ko Narrazioak liburuko izenburuak "Ginebra erregina herbestean"etik, 2011koan "Ginebra erreginaren erbestea"ra egin duen aldakuntza. Esanguratsua da, aurreneko honek erregina non dagoen iradokitzen baitu soilki, bere "benetako" erresumatik aterea dela azpimarratzen du, Mark Twain idazle amerikarraren narrazio arturikoaren izenburua gogoratuz, edota abentura artxigeneroko formula ezagunaren ildotik. Aitzitik 2011ko izenburuak, "Ginebra erreginaren erbestea" formulazioak bere protagonismoa zehazten du modu poskolonialean. Erregina besterendua bizi da, gizarte patriarkalean dagokion ez-tokia iradokiz, eta gisa berean adieraziz bere "egoteko modu" hori dela benetan esanguratsua orain. Ni ez naiz hemengoa liburuko "Ehundegiko dama" ataltxoan (120-122) Ginebra erreginaren erbestearen gaiari buruz dihardu, eta Tennyson poetaren 1850eko The lady of Shalott balada iruzkinduz, eta haren ilustrazio gisa W.H. 
Huntek pintaturiko irudi prerafaelita. Tennysonek gai arturikoetan inspiraturik, Ginebra erreginak bere ehuntze lanetik arreta galdu eta Lanzelot zaldunarengana bideratu zituen bere begiak:

"Bere gela zarratu eta iluneko eginbidea lekoreko maite deiagatik utzi duelarik, haria endredatzen da, eta damaren bizitza hondatzen. Ginebraren istorian bezala, Lanzelot Lakukoa iragan zen orduan ere. Eta begiradagatik, erregerearen erresuma guzia, taula borobila, zalduneriaren mundu guzia hondatu zen. Irlako dama -W.H. Hunt pintoreak esan zuzenez- talaian dagoen arima da, isolamendu hurrin eta ilunean, munduaren deiari amore emanez gero galdu dena. Amodioaren deiari amore emanez gero bere ehundegiko harian endregatuko da, amaraun tragikoan" (1985:123).

Bestalde, Ginebrarenganako pultsio erotikoa da Sarrionandiaren narrazioetako erritmoaren perkusio elementu taigabea, "Ginebra erreginaren erbestea" izenburu adierazgarriaren ondoko paratestuak iradokitzen duen moduan:

"Evak eskuan heldu zuen fruitua hartu zueneko adarra eta harrezkero ez du egundo, ez lehenago ez geroago, adar hori soltatu." Queste del Saint Graal

Ginebra erregina emakume bat baino gehiago da, batetik Eva da, desira ororen iturburu eta, gisa berean, erabat iritsi ezina berak hautatzen ez dituenentzat. Ez Arthur erregeak eta ez Foolek ezin dute eskuratu eta emaztearen jolas erotikoak goiko ganberan zaindu besterik ez dezakete egin. Izan ere Ginebra bezalako emakumeak gizonen menpe daude, haien desiraren objektu dira, baina, halere, beren desira propioaren jabe ere badira. Arthur erregeak haren urratsen taupadak zaindu besterik ez dezake egin "Ezpata arragoan" narrazio osoan iradokitzen den bezala. Aldiz, Ginebraren erakarmen erotikoa zabaltzen da ipuinotan urrezko egurats bat bezala, eta Lanzarote edo Galahad dira Ginebrak hautatuak: heroi mitiko horien garbitasuna eta zuritasuna azpimarratzen da, idealismo nahiz kastitatearen adierazle, analogia poetikoz izaren eta elurraren zuritasunarekin identifikatuz. Aita-semeok Graal Saindua eskuratzeko duin dira, Arthurren erresumaren zoriona eskura lezakete, sarritan bihotz formako kristalezko ontzi gisa irudikatu izan dena. Alabaina, Tennysonen poeman bezala, Ginebraren desirak zapuztuko ditu haien aukerak, modu honetan galduko da Arthurrek "Graal saindua aurkitzeko eta mundura zoriona ekartzeko azkenenengo esperantza" (2011-57). Horregatik, haien leinuaren dohainari iraunarazteko asmo ezkutuaz Arthurrek ez du Ginebraren haurra hilaraziko.

Baina bada zerbait gehiago. Ipuin honetan ez da adulterio baten zigortze biolentoz soilik hitz egiten, zeren Gallahad gazteak beti berekin daraman "liburu gorria" irakurtzen $\mathrm{du}$, hori da definitzen duen osagaia, erregea bere koroak definitzen duen bezala, edo erregina bere edertasunak definitzen duen gisa berean. Liburu gorriak metonimikoki maoismoa seinalatzen du eta haren eramailea iraultzaile bat dela iradokitzen du, horregatik ez da harritzekoa Fool bufoiak objektu hori errekisatzea erreginarengana etorri den une batean, poliziaren funtzioak ere badituela erakutsiz (2011:60). Arthur erregeak ohorearen kodearen legea betetzea hautatu du eta emaztearen ohaidea hil du, ohorearen "legeak bete behar" dituelako, baina horrek izozturik utziko du bera, guziz larrituta Graal Saindua eskuratzeko aukera galdu baita horrela: "Hil egin da Graal sainduaren esperantza, esperoa besterik ez uzteko. Hautsi egin da kristalezko bihotza eta erbesteko lurretan barreiaturik geratu dira puskak, egitasmorik gabe" (2011:61). Arthuren ohore legeak galarazi du zorionaren esperantza, eta, agian metaforikoki, trantsizio ondoko itxaropenen zapuzketaren desenkantoa adierazten du, klabe politiko garaikidean trantsizioaren uneko sentsazioen adierazle 
bilakatzen delarik ipuina: Ginebrak sinbolizatzen duen maitasun desira (bizi pultsioa) eta nazioaren desira bidegurutzean dira.

Euskal Herriari loturiko zantzuak ipuin horietan hainbat dira, baina ez beti elkarrekiko koherenteak fragmentarioak, aitzitik , sarri paradoxikoak ere badira. Hala, leku izen errealetan kokatzen dira (Durango eta Izurtzako etxe, kaleak...) eta jantzi-ohitura kronologikoki inkoherenteak daramatzate (Kamelotekoak nahiz Euskal Herriko nekazarienak nahastuz) eta garai ezberdinetako pertsonez aipamenekin batean ageri dira: Sisifo eta Miletoko Thales, Li Po nahiz Manuel Bandeira, John Donne nahiz Claude Lévi-Strauss, Pedro Pablo Astarloa nahiz Jose Mari Iturralde ${ }^{19}$.

Halere, euskal herritarren aipamen hurbilenak "Ezpata arragoan" narrazioan ageri dira nabarmen: Arthur eta Foolen elkarrizketan beti "esperoan" dauden herritarrez hitz egiten da, eta beharbada ipuina idatzi zen sasoiko Euskal Herriko politikaren auzi nagusiak, hala nola ETAren borroka iraultzailea, indarkeria, erbesteratzea eta itxaropen zapuztuak azaleratzen dira fikzioan. Pentsa daiteke 1978ko Konstituzioan eta 1979ko Estatutuan mamitu zen baldintzapeko demokrazia haren desenkantuaz mintzo dela malenkonia ilunaz. "Ginebra erreginaren erbestea"ko Galahad nor den sumatzen dugun arren, ez dezakegu zehaztu Arthur boteredunak Estatua ala Euskadin sortzen ari zen estatuko boterea errepresentatzen duen. Alegoriak ez du zehaztasunik ematen, ez bada, Arthurren beraren erabakietatik ondorioztatzen: bizirik uzten du Galahad-en semea, eta bere deitoramendua ere hor dago: "larritasun sakon bat". Fool bufoi filosofoak esaten duen moduan, "Esperoa ez da zerbait helduko dela pentsatzea, esperoa bizitzeko modu bat da, zerbaiten faltarekin. Baina falta hori iraganean dago, edo orainean, ez dakit, eta etorkizunean" (2011:202).

"Amorante ausarta" Merlinen narrazioak agertzen ditu ezaugarririk satirikoenak eta ukronia nabarienak, zeren batera nahasirik ikus genitzake bertan lehengo, oraingo eta askoz beranduagoko teknikaren adierazpenak. Adibidez, Merlinez esaten zaigu bere doktore tesia Chicagon argitaratu dela, 5891urtean, eta izenburu guztiz adierazgarria daramala gainera: The city as an artifact. Zientzia fikzio parodikoaren ildorantz egiten du "Amorante ausarta" ipuinak, Merlinen ipuina zibilizazio urbanoaren garapenarekin identifikatuz: hirian tresna hondatuak, tramankulu alferrikakoak, natura hondatzen duen produkzioa, iragarkiak, gilletteak produzitzen dituzten zuhaitzak, baina idazle txarrak, poeta astunak, eta beti alkate kontserbadoreak ere produzitzen ditu! Enumerazio kaotiko honen ironiak zibilizazio dezepzionagarri baten hondamendia iradokitzen digu, eta bere iraganean herexia erlijioso baten jarraitzaileak sutan erre zituztela ahantzita bizitzea. Hiriaren ekfrasi horretan dago iradokita denboraren kontinuitatearen ezinbestekotasuna, baina ahanzturaren erasana ere bai.

Leienda zeltikoen tradizio atlantiko zaharrarekin loturiko pertsonaia misteriotsua da Merlin aztia, baina Sarrionandiaren narrazioan, boterearen laguntzaile teknokrata izateaz gain, "amorante ausarta" da, batez ere, eta bere pultsio erotikoak eskuratu ezin duenaren nahikaria sortzen dio ipuinaren paratestuak dioen moduan: "Amodioan ez duzu, amorante ausarta, bilatzen duzun jabegoa sekula lortuko" Merlin Zaharra

31 Ni ez naiz hemengoa liburuko "Ehundegiko dama" ataltxoan aipatzen da ipuin hauetako intertestualitate artistiko nagusietako bat Edward Burne-Jones zenaren "Merlin Liluratua" laukia, berriro ere sumarazten digularik ipuinon jatorria irudi estatikoak direla, gehienetan, prerafaeliten margolan historikoak. Merlinen paradoxa dago ipuinaren muin-muinean. Etorkizuna igartzeko gai denez, badaki Enare sorginak, Vivianeren izena euskarazko izen batez ordezkatu duen pertsonaia bakarrak lortuko 
Merlin neutralizatzea, ez indarkeriaz, baina bai inteligentziaz eta azerikeriaz, Erregeari eta "hiriari" teknologia gehiago eskaintzea eragotziz. Merlin aztia maitemindu du eta haren hitz magikoak ikasiz, Arthur erregearen laguntzaile teknologikoa desaktibatzeko gai izango da. Etorkizun utopiko batean garaile izango den Enarek gauez jokatzen du eta zuhurtasunez. Izan ere, bere izenak iradoki bezala, gaua heltzean hegaldatzen den hegazti liraina baita, eta izartegi osoa, beraren egintzei lotua imaginatzen du, etxera itzulian datorren armada babesgarri bat bezala.

Enare eta Merlin aztiaren aurrez-aurreko lehian suma genitzake osagai utopiko nagusienak Sarrionandiaren narrazio arturiko sinboliko hauetan. Etorkizuneko jokabiderako iradokizunik argienak hor ditugu. Merlin teknokrata ahaltsua desaktibatzea hiriaren aginpide destruktiboa eragozteko, eta Arthur bere botere naturaz gaindikoaz gabetzeko. Amaiera aldera, itzuli ezina den formula magikoa ikasten du Enarek: "Idebalah". Sorgin hizkeran eta Leonardo da Vincik erabilitako alderantzizko idazkeraren kode sekretua erabiliz, letrak kontrako aldera irakurriz, "halabedi" esan nahi duten hitzok, teknologiaren bidezko inposizio tiranikoaren amaiera zigilatzeko balioko dute.

Gogoratu behar da "Eguzkia ortzi urdinean" (1985) ipuinean naturaren destrukzioa iradoki zuela pertsonaia arturikoek protagonizaturiko narrazio fantastikoaren bidez, kezka kontrakulturalen gune nagusietako bat azaleratuz. Presebal zaldun ibiltariaren pasadizo bat kontatzen zaigu ipuin hartan, eta ilusio mimetikoa hausten duten erreferentzia metafikzionalek ohartarazten digute liburu bateko letrak eta ilustrazioak narratzen ari zaigula: "Presebal liburuko heroiak, leiendako animalia ikusiz gero..." (2011: 146) dioelarik. Adarbakoitza Naturaren altxor ukiezina da Antzitateko mitologian eta Erdi Aroan hedatua da Sarrionandiak aurkezten duen ezaugarriekin: "La licorne est un animal très sauvage si bien que, pour s'en emparer, on est obligé d'avoir recours à une vierge. L'animal, en la voyant, vient à elle, se couche sur son sein et se laisse prendre." (Honorius dit d'Autun, Spéculum Ecclesiae, XII. m.)

Beharbada narrazio hauxe da jauregi gotikoetako erretaula nahiz tapiz mediebalen alegorien elementu gehien biltzen dituen narrazioa. Bere erredakzioan, Erdi Arotik kronologia zehatzik gabe gugana iritsi diren testuen estiloaren zantzuak nabari ditzakegu. Hala, XV mendeko tapiz bilduma ospetsu batean "La dame à la licorne" irudikatzen den moduan, oihal gorriaren hondoraren gainean, urre, orlegi eta urdinez irudikaturiko narrazioa ematen da, eta zentzumenen erakarmena alegorizatzen duten bost tapizen ondoren, “À Mon Seuil Désir" legenda idatzi den Unikornioaren eta Dontzeilaren arteko maitasuna kortesauaren azken irudiaz isten $\mathrm{da}^{20}$. Maitasun gortesauaren urrats sensorialaren eta intelektualaren ibilibidea egiten du Sarrionandiaren narrazioak ere maitasunaren kunplimendua heldu aurretik, tapizean damak eta adarbakoitzak elkarri eskaintzea egiten duten moduan. "Dontzeila" hitza erabiliz iradokitzen du iurretarrak zalduneria eleberrietako maitasun gortesauaren protagonistaren sagratutasuna, izendatze hori dagoelako erreserbaturik zaldunaren damarentzat bezala Ama Birginarentzat, dakigunez, biak identifikatzen baitira ikonografia mediebalean. Hitzen magia oraingoan, hautapen lexikoaren bidez eraikia $\mathrm{da}$, eta paisaiaren ekfrasi gotikoaren bidez. Bestalde, magia hori osatzen dute balada zahar edo eresien hizkera eta iruditeriaren alusioek. Ikus ditzagun iradokizun tragiko zenbait:

"Adarbakoitz errea afalduko dute gaur, oreinarena baino samurragoa omen da okela. Halaere, kontrario da dontzeila, behiala dontzeila izandako andere triste 
hori. Anderea Presebalek besoetan daraman haurrarekin, hirurak abiatu dira ezkutuan gaztelutik lekora ilunarekin eta zaparradarekin batera" (2011:152) da "Eguzkia ortzi urdinean", eta parodiarik ez da nabari. Ipuin orientalen taxu sinbolikoaz horniturik, fantasia arturiko honetan zalduneria mundu erratikotik mundu fantastiko baterantz salto egiten du Presebal heroiak ${ }^{21}$. Fikzio maila batetik bestera egiten du jauzi oharkabean, sagarrondoaren adarretan gora doalarik. Beste mundu miresgarri bateranzko "atea" aurkitu du, ipuin miresgarrietan ohi den moduan. Bere esperientzia oniriko hori ezin deitoragarriagoa da, ordea, eta lokamuts bilakatu zaion ametsetik, denboraren tuneletik esnatzean, lehengo errealitate zentzugabean jarraitzen da, astun, nekatu eta trebeziarik gabe. Xederik gabe. 


\section{Tradizioa eta sinkretismoa}

$\mathrm{Ni}$ ez naiz hemengoa liburuko atal baten izenburua da tradizioa eta sinkretismoa elkartzen dituena. Bertan, Sarrionandiak dioskunez, historian lehenago sekula baino gehiago, zabalik dago mundu guzia eta, sorterriaren ez ezik, mundu horren partaide sentitzen gara guziok. Idea hori ilustratzeko metafora eder batez baliazten da: "Egungo kultural ez dira sustraiak bere lurrean eta arramak ere, aidera, beti leku berberean dituen zuhaitzaren modukoak" (1985:144). Ildo horretan, irakurtzea komeni da, nire ustez, Sarrionandiaren ipuin arturikoak.

Sarrionandiaren ipuinotan zenbait ikerlarik egitasmo nazionalak duen garrantzia azpimarratu dute. Juan Zarandona gai arturikoetan aditua den irakasleak ${ }^{22}$, seinalatu izan du Espainiako idazle periferikoek, katalanek, euskaldunek eta galiziarrek leienda arturikoak baliatu dituztela eta manipulatu, euren kultura, hizkuntza eta nazio eraikuntza sendotzeko. Hona hemen bere 2007ko bere artikuluaren laburpenean dioena:

"El presente artículo se esforzará por poner de relieve el curioso hecho de que en España, algunos escritores periféricos que adquirieron el compromiso de escribir en sus lenguas minoritarias, Catalán, Gallego y Vasco, se aprovecharon de la leyenda artúrica, la manipularon y consiguieron hacerla apoyar su exigente causa de construcción y reconstrucción de una cultura, lengua, nación e identidad. Galicia, la húmeda región del noroeste español que decidió, de manera colectiva, convertirse en una plena nación celta, representa el ejemplo más sorprendente de este fenómeno que consiguió aunar el añejo mito artúrico con los acontecimientos del presente contemporáneo." (2007: 217)

Zarandonak erabilera "oportunista"tzat gisan aipatzen du literatur tradizioaren erabilera hipertestuala, narrazioen berridazketa horien legitimitatea zalantzan jarriz, edo prozesu estonagarritzat aipatuz. Ikuspegi kolonial baten zantzuak sumatzen dira bere adierazpenetan, bereziki darabilen lexikoan sumatzen denez (aprovechar, manipular, exigente...). Garai eta gizarte guztietan garatu izan dira aurreko mendeetako narratiba fundatzaileen apropiazioak, eduki sinboliko propioz jantzi eta norbere narratiba eraikitzeko. Iragana errepositorio edo biltegi baten gisa baliatu da betidanik, fikzioen bidez eduki kultural sinbolikoz janzteko narratiba berriak. Are gehiago, Arthuro erregearen inguruko narrazioen bilakaera transtestuala hain ongi aztertua delarik, argiro erakusten digu literaturaren harilkatze eta desarilkatze luzea, idazte eta berridazte katea amaiezina dela.

Izan ere "Ni ez naiz hemengoa" egunkariko "Literatura historikoaren gainean" (1985:46-48) ataltxoan, Sarrionandiak adierazi zuenez, ziklo arturikoa ingelesen kontzientzia kolektiboa indartzeko erabili bazen ere, mitoen oihal komunari dagokio: "iraganeko pertsonaia, gertaera eta istorio batzu eredutzat dira, gai edo eredu historiko edo literario gisa." eta "zutabe finko eta zabal bat" dira idazlearentzat.

Hortaz, gain, Zarandonak ez du egoki sumatu Sarrionandiak darabilen narratzailearen transtextualitatearen erregistroa zein izan den: parodia eta hizkera sinbolikoa. Ikusiak ditugun testu garaikide gehienetan, berridazketa historiografikoek asmo kritikosatirikoa edo ludikoa izan dute. Aldiz, gure garaian, zirkuito komertzialetatik at, kontaahalak dira Genettek paratestualitatearen azterketan asmo "serioa" z soilik eginikoak.

Terminologia genetteanoaren xehetasunetan sakontzean erreparatzen den moduan, idazleak beste idazleen testuak berridazten ditu, haien argumentuaren leku-denbora 
ezaugarriak aldatuz transposizio soila eginez, edo haien estiloa imitatuz transposizio konplexua garatuz. Halere, modalitate ezberdinak sor litezke egilearen asmoaren arabera: ludikoa satirikoa eta serioa. Nolanahi ere, sarritan ez da erraza asmo satirikoaren eta ludikoaren artean bereizketa egitea eta irakurlearen baitan dago bere konplizitatearen arabera kritika eta irri jostariaren artean bereizten asmatzea. Sarrionandiaren kasuan, bere parodiak tristea kalifikazioa jaso du hasierarik beretik. Beraz, esan genezake Sarrionandiaren ipuinotan modu kritikoan aztertzen direla Euskal Herriko laurogeitako bizitza kulturala eta politikoa zauritzen zuten auzi serioak, eta zaurgarritasun horrek ematen diola bere parodiari malenkonia ezin tristeagoa.

Iñaki Aldekoak, egilearen asmo estetikoari ematen dio garrantzia gehien: "Sarrionandia soñó en sus poemas y cuentos con la Edad Media dominada por las leyendas artúricas y el ciclo bretón del Santo Grial. El rey Arturo, Ginebra, Galahad, Fool, Perceval, Lanzarote y Merlín, junto a la herejía tardo-medieval de su Durango natal, forman el paisaje de su imaginario históricamente más distanciado.”23.

Aldekoak egoki seinalatu zuen moduan, Grial Saiduaren bilaketak eta Kameloteko gizarte perfektuaren ereduak kristautasunaren lege morala begiratzearekin estuki lotu zituzten Erdi Aroan.Sarrionandiaren ipuinetan, ordea, horrek ez du inolako islarik, Grialaren bilaketak helburu mundutarrak ditu beretzat. Aldekoaren ustez, Sarrionandiaren interes nagusia Erdi Aroko paisaiaren erromantizismoan kokaturiko ohorezko legeak eta epikak agintzen duen gizarte bat birsortzea da, batez ere paisaia fisiko eta morala estetikoki lantzen duelarik ${ }^{24}$.

Aurreko pasarteetan erakusten saiatu garen moduan, gure iritziz, giro dramatikoaren eta parodiaren artean dauden narrazio fragmentarioak ondu ditu Sarrionandiak, horretarako metaforaren edertasunez eta deskripzio analogikoen diztiraz hornitzen dituelarik. Halere, narrazioaren muina bera, pertsonaien esanen eta eginen edukia ezin serioagoa da, batez ere metafora horien interpretazioa 1970-90ko hamarkadako gertakarien testuinguruan idatziak direla pentsatzen bada eta egilearen bizi baldintza konkretuak ezagutzen badira. 2011ko berredizioari eginiko hitzaurrean dioenaren arabera, Sarrionandiak uste du ipuinok idatz zituen garaian "ez da egia "literatura" ari ginenik bakarrik egiten, geure bizimodua eta gizarte egiturak ere aldatzeko ilusioarekin eta frustrazioarekin ari ginelako" (2011:8).

51 Juan Zarandonak, aldiz, uste du haren ipuinek "exhiben interpretaciones muy originales de los motivos artúricos, ambientados en un contexto rural vasco, y adornados con constantes referencias al nacionalismo vasco." (2007:229) Eta egiaz auzi sozio-politikoa implikatzen duten hartu-emanak agertzen ditu narrazioen dialogismoak, aipatu dugun moduan, baina ez da Maloryl bezala bere nazioaren kontzientzia kolektiboa indartzeko literatura historikoa egiten ari. Nazioaz eta botereaz hausnartu du, baina baita klase auzia eta gizon-emakumeon genero auzia gizarte patriarkalean: gizarte arau eta ohore-lege mediebalek dakarten zoritxarraz. Halere, oroz gainetik, giza izakerari buruzko hausnarketari erreparatzen dio, desira inkonsziente edo aitortu gabeek duten indarrari.

Narrazioak egintzak eta esanak erakusten ditu, baina kontalariaren begiak, gizon eta emakumeen desiren pultsioak jartzen ditu fokupean, generoari buruzko ansietate baten garrantzia azpimarratuz: tentsioa ezartzen du nork bere genero rolean pairatzen dituen muga hertsatzaileetan. Emakume protagonisten jokabideak ohorezko araudia azpikoz gora itzulikatzen dute txintik esan gabe: Ginebra erreginak adarrak jartzen dizkio agintariari, desira propio baten jabe dela erakutsiz, baina Adarbakoitzaren 
dontzeila bezala indarrez menperatua izango da. Enare, berriz, bere erakarmen sexualaz baliatuko da Merlinen jakituria bereganatzeko, denek ematen dioten "puta" izenaz axolarik gabe. Gudaren logika maskulinoa dute mintzagai ipuinok eta gizarte patriarkalaren kritika zorrotza eta ironikoa egiten dute, bereziki zaldungoaren araudiaren paradoxak agerian jarriz: ohorearen legea inposatzen da eta maitasun kortesaua, baina indarraren eta gerlaren pulsio suntsitzaileak gailentzen dira, eta emakumearen desiraren adierazpena ezinezko egiten da. Ondorioz, maitasuna ezinezkoa da eta zoriontasuna ere bai.

Errealitatea, errepresentazioa eta testualitatea izanik posmodernismoaren eztabaidagai nagusiak ez da harrigarri genero posmoderno nagusia eleberria eta ipuina izatea, eta hartan mamituak egotea, Sarrionandiaren ipuinotan bezala, ezaugarri nagusietako zenbait: auto-reflexibitatea, fragmentazioa, diskontinuitatea, pertsonairen disoluzioa, intertextualitatea, aniztasuna, ludismoa, parodia, egilea bera testuan sartzea autofikzioaren bidez, etabar. Horrek ez du esan nahi, erakusten saiatu garenez, lorpen artistikoen arloan anbiziorik ez dutenik eta eredu arturikoei egin nahi dizkieten aportazioek eduki moral sakonik ez dutenik. Izan ere, El País-ek eginiko elkarrizketa batean Paloma Díaz-Mas irakasleak esan zuen moduan, "Escribir sobre el medioevo es sólo una forma irónica de escribir sobre la actualidad" ${ }^{25}$.

Sarrionandiak ere, antzerako ideia trasmitzen du ipuinon bildumaren hitzaurrean:

"Errealismotik urrun (baina zenbaitetan ezinezkoa zen) bai gaien, bai kontaeren, bai hizkuntzaren aldetik, beste errealitate batzuk kreatzea ${ }^{26}$ zen intentzioa. Hau da dimentsio literarioko beste mundu, sentsibilitate eta hizkera batzuk sortzea errealitate errealaren gainean" (2011:8)

Azken ondorio batzuk zehazte aldera, ipuinon irakurketan maila ezberdinak bereiz daitezkeela ikusten da, lehenik, maila psikologikoan erosen eta thanatosen pultsioa eta maitasunaren ezintasuna ditu mintzagai, gizartea zartatzen duten gatazkak iradokiz. Bigarrenik, maila sinbolikoan, gatazka horiek beroiek Sarrionandiaren narrazioetan aukera galduak bilakatzen dira, boterearen kontrol grinez gizartean sortzen diren mugimendu susmagarriak indarrez suntsitzera jotzen baita, nazioaren etorkizuna zapuztuz, eta herria beti "esperoan" egotera kondenatuz. Utopiaren etorkizun urrunean soilik hasiko dira gauzak aldatzen: emakumearen desira boterearen sorginkeriatik askatuko da gizarte patriarkal eta ierarkizatuaren loturetatik.

Honenbestez, beraz, bat etorriko gara J. Kortazarrekin esaten duenean errealitatearen eta fikzioaren arteko muga lausoa eta arrazionalismoanen kamustasun posmodernoa iradokitzen digutela ipuinok (Kortazar, 2005, 54-59). Eta honen harira, ezin utzizkoa deritzogu Aiora Jakak buruturiko tesi dokotorala ere aipatzea, modu zabalean garatzen baititu egilearen idazle eta itzultzaile poetiketan posmodernismoak izandako eraginaren zantzuak. Jaka irakaslearen ustez, Sarrionandiak "Utopian sinesteari utzi gabe eta bere balio eta printzipioei uko egin gabe, zalantzan jartzen du balio horien unibertsaltasuna, eta gizabanako eta talde bakoitzari zor zaiona emango dion gizarte justuago baten aldeko erantzukizuna hartzen du" (2012:358) ${ }^{27}$.

Ipuin horietan ez dira gure ustez, ondorioz, Erdi Aroko baloreak edo jarrera heroikoak proposatzen gaur egungo errealitatea argitzeko eredu epiko-nazional gisa, eta are gutxiago gaurko mundu arruntari ihes egiteko ebasio-ipuin miresgarri eta lirikotzat. Aitzitik, Sarrionandiak Erdi Aroko narrazio arturikoak berridatzi baditu, gure garai posmodernoko denboraren joanera paradoxikoaz hitz egiteko helburuz egin du: denboraren norabidea zein den ez dakigularik ere, gizon-emakumeon bizitzak bilaketa 
bat izaten jarraitzen du, eguzkiak ortzi urdinean nabigatzen eta gure egunak argitzen jarraitzen duen bitartean. Ginebra eta Lancelot, Arthuro eta Gallahad, Presebal eta Adarbakoitza/Dontzeila, Merlin eta Enareren joan-etorriek ez dute etenik, baina gure garaiotan haien dramaz hitz egiteko erabiltzen duen erregistroa parodia tristea eta ukronia dira, posmodernitatearen genero nagusietako bi. Izan ere, Narrazioak liburuari erantsitako paratestuetako batean zioen moduan $^{28}$, Mugarrago azpian datzan Etxaburuko dorreak, "hutsik dagoela dirudi, baina hortxe bizi dira behialako heroeak, zibilizazio bazterreko eskasian eta zoriona mundura noiz etorriko ote den esperoan" $(1983,131)$.

Horregatik baiezta genezake Sarrionandiaren lan horietan argiro ikus daitekeela mamiturik Ni ez naiz hemengoa liburuan adierazi zuen munduko literaturaren eta euskal tradizioaren erroen besarkadaren ideia posmodernoaren garrantzia, imajinen bidez hedaturiko lengoaia ikonikoen unibertsalizazioaren ondoriozkoa. HaiNbesterainokoa da hizkera horren indarra non fotografia, ikusentzunezko komunikabideen bidez imajinak mundu guztira hedatu eta popularizatu duen « oihal mitiko komun » bat, eta mundu guziko biztanleek eskenario berbera zapaltzen dugulako kontzientzia dugun. Hausnarketa guziz interesgarri horien ondarrean berresten du egileak gure artikuluaren funtsa laburki adierazia: "Unibertsalitatea eta sinkretismoa gure aroaren ezaugarri izateaz gainera, jakintzaren, kreazioaren eta libertatearen oinarri dira" (1985: 148).

\section{BIBLIOGRAPHIE}

Aldekoa, I. 1996-1997. "Paganismo y última poesía vasca" in Revista de lenguas y literaturas catalana, gallega y vasca, ISSN 1130-8508, 5., 1996-1997, 315-324.

Atxaga, B. 2012. “Ni, Jean Baptiste Hargous” in Obabakoak, Erein, 2012, 317-322.

Caballero Bonald, J. M. 2012. "Alvaro Cunqueiro o el retablo de las maravillas", Cuadernos hispanoamericanos, ISSN 0011-250X, № 743, 2012, págs. 95-100),

Castells, Manuel. 1997. La era de la información. vol. 1: La sociedad red. Alianza Editorial. Madrid, 1997. Pág. 35.

Diéguez, M.L. 1988. « Entrevista con Paloma Díaz-Mas », Revista de Estudios Hispánicos 22.1 (enero 1988), pp. 77-91 [79].

Jaka, Aiora. 2012. Itzulpenari buruzko gogoeta eta itzulpen-praktika Joseba Sarrionandiaren lanetan (Euskaltzaindia, Bilbo, 2012).

Jameson, Fredric. 2005. El posmodernismo o la lógica cultural del capitalismo avanzado. Paidós. Buenos Aires, 2005. Pág. 97.

Jarazo Álvarez, Rubén. 2010. “La influencia de Thomas Malory y la figura de Merlín en la obra periódica de Álvaro Cunqueiro: Un caso de estudio”.

Jarazo Álvarez, Rubén. 2010. Oceánide. URL: http://oceanide.netne.net/articulos/art2-8.php 
Otaegi, M.L. 1998. "Joseba Sarrionandia o el destino del viejo marino" in "Letras vascas hoy", Insula, $\mathrm{n}^{\circ} 623,1998$, págs. 16-18. ISSN 0020-4536.

Otaegi, M. L. 2000. Joseba Sarrionandia. Marinel zaharraren kantua, [Joseba Sarrionandia. El canto del viejo marino], Labayru-BBK, 2000. ISBN 84-89816-98-0.

Stevenson, R.L. 1877. “A lodging for the night”, New Arabian Nights, 1877.

Zarandona, J. M. (ed) Cuaderno de Camelot, Cultura, Literatura y traduccion artúrica, Univ. De Valladolid, Soria, 2002, 143-203.

Zarandona, J. M., 2007. “El impacto de la literatura artúrica en la construcción de identidades culturales y nacionales periféricas en la España contemporánea: Cataluña, Galicia y el País Vasco", LINGÜÍSTICA Y LITERATURA, No. 51, 2007) pp. 217-230.

Zarandona, J. M. 2003. "Los cuentos artúricos de Joseba Sarrionandia” in cuaderno de camelot cultura, literatura y traducción artúrica, 2003.Universidad de Valladolid.

Zarandona, J. M., 2001. Alfred Lord Tennyson y la literatura artúrica española de los siglos XIX y XX: Traducción, Manipulación e Intertextualidad. Zaragoza: Universidad de Zaragoza 2001.

\section{NOTES}

1. Ikus. Otaegi, M.L. "Joseba Sarrionandia o el destino del viejo marino" in "Letras vascas hoy", Insula, $\mathrm{n}^{\circ}$ 623, 1998, págs. 16-18. ISSN 0020-4536. Otaegi, M. L. Joseba Sarrionandia. Marinel zaharraren kantua, [Joseba Sarrionandia. El canto del viejo marino], Labayru-BBK, 2000. ISBN 84-89816-98-0.

2. Ikus J. Kortazar (2000 :238) M.J. Olaziregi (2002), I. Aldekoa (Euskal literaturaren historia, 2008, 318-319)

3. Stevenson, R.L. “A lodging for the night”, New Arabian Nights, 1877.

4. Ipar aldeko orduak, 1990.

5. Narrazioak, 1983.

6. ATXAGA, B. "Ni, Jean Baptiste Hargous" in Obabakoak, Erein, 2012, 317-322. Berridazketa sakona izan duen narrazioa da, baina lehen bertsioan, Joseba Sarriionandia, Pierre de Broc izeneko pertsonaia historikoren beste izena da.

7. Aipagarria da, ordea, 2011ko edizioan pasarte hori eraldatua ageri dela (2011:313)

8. Ikus ETXEBERRIA, H., Bost idazle, 131. Online http://alua.mundua.com/wp-content/uploads/ 2006/11/bost-idazle.pdf [Azken kontsulta 30/05/2015]

9. JAMESON, Frederic. El posmodernismo o la lógica cultural del capitalismo avanzado. Paidós. Buenos Aires, 2005. Pág. 97.

10. Ikus CASTELLS, Manuel. La era de la información. vol. 1: La sociedad red. Alianza Editorial. Madrid, 1997. 35.

11. Wace poeta normandoak jaso zuen lema hori Roman de Brut narrazio bertsifikatuan (c. 1155).

12. Durangoko idazleaz ari denean autorreferentzia bat egiten duela dirudi, Sarrionandiak, herriak esperoan egoteari utzirik esperantza zer den ikas dezan helburutzat hartuko lukeena, autoironiaz agian?

13. Maloryren bertsioak iturri frantsesetatik edaten du, Arthurren zaldun aristokratikoaren izaera azpimarratzen du, heroi britainiar bat moldatu arte. Wacek sartu zuen Mahai Biribilaren osagaia (c.1150). Arthur Mordred-en aurkako azken batailan hitzen dela esaten du Maloryk, baina Waceren bertsioan zabalik uzten da auzia Arthur zauritua bai, baina atzerrian zain dago itzuli eta bere erresuma berreskuratzeko: "Rex quondam, rexque futurus". Wace-ren bertsiotik sortuko zen Chrétien de Troyes-ena, eta hari elkartuko zitzaizkion ondoren Tristram, Lanzarote eta Grial- 
aren istorioak. Frantsesez, Prose Lanzarote edo Ciclo Vulgata deiturikoak hiru erromantze biltzen zituen : lehenik Lancelot, Arthurren bizitza eta amodioa Ginebrarekin ; bestetik, La Quête $d u$ Sant Grial, osagai erlijiosoen gunea, non kastitatearen garrantzia azpimarratzen zen Galahaden meritutzat Griala eskuratzeko, eta azkenik, La Mort le roi Artu, Lanzaroteren adulterioaren mendeku bila joatean, Mordredek eginiko traizioaren ondorioz hiltzen da.

14. Garaitsukoak dira H.G. Wells-en "The Chronic Argonauts" (1888) eta The Time Machine (1895) nahiz Edward Bellamyren Looking Backward, (1888) liburuekin batean.

15. Sarrionandia eta Xose Luis Mendez Ferrinen narratibaren hartu-emanak iradokitzen ditu Jon Kortazarrek, bereziki, Percibal e outras historias (1957) liburuko narrazioak abiapuntutzat harturik. KORTAZAR, J. J. Sarrionandiaren ipuingintza. Zuhaitz erromesa, Utriusque Vasconiae, Donostia, (2005, 47-51).

16. Ibidem 131.

17. Ikus Ruben JARAZO ALVAREZ, "La influencia de Thomas Malory y la figura de Merlín en la obra periódica de Álvaro Cunqueiro : Un caso de estudio”. Rubén Jarazo Álvarezek (Universidade da Coruña, Spain) in Oceánide 2010 URL: http://oceanide.netne.net/articulos/art2-8.php

18. J.M. Caballero Bonald "Alvaro Cunqueiro o el retablo de las maravillas", Cuadernos hispanoamericanos, ISSN 0011-250X, № 743, 2012, págs. 95-100),

19. Ikus Arrate Osinagak Oihana Mariezkurrenak eta Nahia Zarzosak ipuin arturiko hauen gaztelaniazko itzulpenenaren hitzaurre gisa emaniko azalpen zehatzak. Juan Miguel Zarandona (ed) Cuaderno de Camelot, Cultura, Literatura y traduccion artúrica, Univ. De Valladolid, Soria, 2002, 143-203.

20. Musée Nationa de Moyen Age, Paris.

21. Ipuin honetako protagonista den Presebalen izena ere euskal testu zaharrak dakartza akordura: "Mondragoeko erreketaren kantak" izendatuak. Percival zaldun arturikoaren deituraren euskal bertsioa da Euskaltzaindiaren izendegiaren arabera. Besteak beste, balada zahar epiko baten lerroetan agertzen den gerlarietako baten deitura da: "Gomez andia zanarren/ an zan Presebal Bere, bai Joanikote bere, Magdalenaan an ei dautza/ biola tronpeta bage." Julen Arriolabengoa, "Los textos vascos en la Crónica Ibarguen-Cachopín.", On-line esteka: http:// www.ehu.eus/monumenta/pdf/mintegia2008/Arriolabengoa-

Los_textos_vascos_en_la_Cronica_Ibarguen-Cachopin.pdf) [Azken kontsulta 30/05/2015]

22. Bibliografia zabala du gaiari buruz eta Sarrionandiaren ipuinez:

ZARANDONA, J. M., "El impacto de la literatura artúrica en la construcción de identidades culturales y nacionales periféricas en la España contemporánea: Cataluña, Galicia y el País Vasco", LINGÜÍSTICA Y LITERATURA, No. 51, 2007) pp. 217-230.

ZARANDONA, J. M. "Los cuentos artúricos de Joseba Sarrionandia" in cuaderno de camelot - cultura, literatura y traducción artúrica, 2003.Universidad de Valladolid.

ZARANDONA, J. M., Alfred Lord Tennyson y la literatura artúrica española de los siglos XIX y XX: Traducción, Manipulación e Intertextualidad. Zaragoza: Universidad de Zaragoza 2001.

23. Iñaki Aldekoa, "Paganismo y última poesía vasca" in Revista de lenguas y literaturas catalana, gallega y vasca, ISSN 1130-8508, 5., 1996-1997, 315-324.

24. "Si Mirande rechazó de modo violento y visceral toda tradición que tuviera alguna reminiscencia cristiana, Sarrionandia simplemente la ignora, tomando de Arturo y sus compañeros la faceta caballeresca. El clérigo Geofrey de Monmouth describe el rey Arturo como defensor de los valores cristianos contra los bárbaros sajones, pero Sarrionandia romantiza el medievo y su recreación de Arturo y Ginebra poco tienen que ver con las mitificaciones cristianas. El paisaje medieval de Sarrionandia es, preferentemente pues, romántico y poético, es fundamentalmente un paisaje estetizado" (Aldekoa1997: 320-321)

25. DIÉGUEZ, M.L. “Entrevista con Paloma Díaz-Mas”, Revista de Estudios Hispánicos 22.1 (enero 1988), pp. 77-91 [79].

26. Azpimarra nirea. 
27. JAKA, Aiora, Itzulpenari buruzko gogoeta eta itzulpen-praktika Joseba Sarrionandiaren lanetan (Euskaltzaindia, Bilbo, 2012).

28. Ikus "Narrazioei ohar batzu" $(1983,131)$

\section{RÉSUMÉS}

Artikulu honetan iragan mitikoaren berridazketak euskal literaturan ekarritako emaitza interesgarri batzuk aztertuko dira, zehazki, Joseba Sarrionandiak 1983-1990 artean argitaraturiko narrazio arturikoak irakurtzeko moduak. Jean Bodelek matiere de Bretaigne deituriko ziklo narratiboaren reapropiazio horiekin, narrazio historikomitiko hura, berreraikitzearen ildotik jo beharrean, kontakizun anakronikoak proposatu dizkigu egileak, eta euskal lurraldera ekarriz haien irakurketa klabe parodikoan iradoki digu. Hala, ikusiko dugu, narrazio fantastikoen esparruko berridazketa ukronikoen tradizio luzeari jarraituz, idazle iurretarrak ere bere garaiko gatazkei buruz hitz egin duela, garai eta testuinguru mitiko guztiz ezagunetan kokaturiko fikzio fragmentuen bidez eta metaforaren hizkuntzaz segretuki mintzatuz.

Aztergaitzat hartuko ditugu, beraz, Joseba Sarrionandiaren lau narrazio arturikoak: "Ginebra erreginaren erbestea", "Ezpata arragoan" "Eguzkiak ortze urdinean" eta "Amorante ausarta". Berorien ildo berean, historian kokaturiko beste zenbait berridazketa hipertestual ere jorratuko dira, hala nola, "Kristalezko bihotza", "Disiecti membra poetae" eta "Oroitzera eseri". Egileak aitortu zuen moduan $(2011,8)$, testuok hiru ipuin liburu jarraituetan argitaratu zituen Narrazioak (1983), Atabala eta euria (1986) eta Ipar aldeko orduak (1990) eta egitasmo literario bati atxikirik idatzi zituen "ipuin literario molde bat sortzeko" asmoari, hain zuzen. Artikulu honetako aipamenak Narrazio guztiak (1979-1990) (Elkar 2011) edizioan oinarrituko dira; alabaina, 1983,1986 eta 1990 ko bertsioetatik 2011kora eginiko aldakuntza adierazgarri zenbait ere aipatuko dira oin oharretan, idazlearen berridazte prozesu amaiezinaren lekukotza adierazgarri gisa.

Era berean, gisa horretako berrezarpen literario aipagarrirekin alderaketak eginez, egilearen asmoei buruzko hipotesia garatzen ere saiatuko gara, ikasketa kulturalen ildoaren kontzeptuez baliatuz. Izan ere, gurean Jon Mirandek egin zuen gisa berean, erromantizismoaren eraginpeko apropiazioen ildo berean irakurri izan badira ere, uste dugu posmodernitatean eginiko berridazketen haritik, XIX mendeko euskal literatura erromantikoaren asmo nazionalistetatik aldendu zela iurretarra. Aitzitik, parodiaren, ukroniaren eta literatura fantastikoaren erregistroan mintzatu zela iradoki nahi dugu, batetik auzi soziopolitiko garaikidearen koordenadetan kokatu zuela, eta bestetik giza desiretan sakontzen duten berridazketa interesgarriak eskaini zizkigula.

\section{INDEX}

Thèmes : littérature 
AUTEUR

MARIA LOURDES OTAEGI IMAZ

Euskal Herriko Unibertsitatea UPV/EHU

lourdes.otaegui@ehu.eus 